\title{
First Automated Stroke Imaging Evaluation via Electronic Alberta Stroke Program Early CT Score in a Mobile Stroke Unit
}

\author{
Iris Quasar Grunwald ${ }^{a, b}$ Andreas Ragoschke-Schumm ${ }^{c}$ Michael Kettner ${ }^{d}$ \\ Lenka Schwindling $^{c}$ Safwan Roumiad Stefan Helwig ${ }^{c}$ Matthias Manitz ${ }^{c}$ \\ Silke Walter ${ }^{c}$ Umut Yilmaz $^{c}$ Eric Greveson ${ }^{b}$ Martin Lesmeister ${ }^{c}$ \\ Wolfgang Reith ${ }^{d}$ Klaus Fassbender ${ }^{c}$ \\ ${ }^{a}$ Department of Neuroscience, Anglia Ruskin University, Chelmsford, Essex, and b Brainomix Limited, Summertown, \\ Oxford, UK; ${ }^{\mathrm{C} D e p a r t m e n t}$ of Neurology, and ${ }^{\mathrm{d}}$ Institute of Neuroradiology, Saarland University Medical Center, \\ Homburg, Germany
}

\section{Key Words}

Alberta Stroke Program Early CT Score - Electronic ASPECTS - Computed tomography - Mobile stroke unit . Stroke $\cdot$ Pre-hospital care

\begin{abstract}
Background: Recently, a mobile stroke unit (MSU) was shown to facilitate acute stroke treatment directly at the emergency site. The neuroradiological expertise of the MSU is improved by its ability to detect early ischemic damage via automatic electronic (e) evaluation of CT scans using a novel software program that calculates the electronic Alberta Stroke Program Early CT Score (e-ASPECTS). Methods: The feasibility of integrating e-ASPECTS into an ambulance was examined, and the clinical integration and utility of the software in 15 consecutive cases evaluated. Results: Implementation of e-ASPECTS onto the MSU and into the prehospital stroke management was feasible. The values of e-ASPECTS matched with the results of conventional neuroradiologic analysis by the MSU team. The potential benefits of e-ASPECTS were illustrated by three cases. In case 1, excluding early infarct signs supported the decision to directly perform prehospital thrombolysis. In case 2, in which stroke was
\end{abstract}

\section{KARGER}

(C) 2016 S. Karger AG, Basel

1015-9770/16/0426-0332\$39.50/0

E-Mail karger@karger.com

www.karger.com/ced caused by large-vessel occlusion, the high e-ASPECTS value supported the decision to initiate intra-arterial treatment and triage the patient to a comprehensive stroke center. In case 3 , the e-ASPECTS value was 10 , indicating the absence of early infarct signs despite pre-existing cerebral microangiopathy and macroangiopathy, a finding indicating the program's robustness against artefacts. Conclusions: This study on the integration of e-ASPECTS into the prehospital stroke management via a MSU showed for the first time that such integration is feasible, and aids both decision regarding the treatment option and the triage regarding the most appropriate target hospital.

(c) 2016 S. Karger AG, Basel

\section{Introduction}

In the management of acute stroke, 'time is brain' [1]. A mobile stroke unit (MSU), incorporating all the tools necessary for guideline-adherent and etiology-specific treatment directly at the emergency site, was proposed in 2003 [2] and shown to facilitate prehospital thrombolysis

I.Q.G. and A.R.-S. contributed equally to this paper. 
in 2009 [3]. The MSU is an ambulance that includes CT scan for multimodal imaging with a quality comparable to that of a stationary CT scanner [4]; a point-of-care laboratory system [5]; and a telemedicine connection to the hospital $[2,3]$. A first randomized trial of the MSU found a $50 \%$ reduction in delay from stroke onset to treatment [6].

Currently, programs for prehospital stroke treatment are in operation at several stroke centers [7-14]. Reports from these programs confirm the enormous time gain associated with prehospital stroke treatment and show that treatment rates can be significantly increased [9].

More importantly, prior to providing successful recanalization therapy and reducing the risk of hemorrhage, the results of CT scans must exclude signs of established ischemia. A post-hoc analysis of the European Cooperative Acute Stroke Study found that the presence of early signs of infarction was an important predictor of poorer response to intravenous (IV) thrombolysis [15] and a higher rate of adverse effects [16].

The interpretation of CT scans performed during the first hours after suspected stroke is often difficult [15], because the interpretation of subtle signs such as loss of the grey-white matter interface or parenchymal hypoattenuation requires substantial expertise [17] and is subject to considerable interrater variability $[18,19]$. As a solution to this problem, the Alberta Stroke Program Early CT Score (ASPECTS) was proposed. This is a standardized topographic system for scoring CT scans performed in the setting of acute ischemic stroke. It divides the territory of the middle cerebral artery (MCA) into 10 areas of interest within 2 specified levels [20].

The ASPECTS value has been shown to be associated with vascular pathology $[21,22]$ and is a simple and accurate predictor of functional outcome after thrombolytic treatment $[20,23,24]$. Patients with an ASPECTS value higher than 7 will probably respond to treatment, whereas those with a value lower than 5 are much less likely to benefit [25]. Thus, the use of ASPECTS value has been recommended by the American Society of Neuroradiology [26]. More recently, ASPECTS has also been used for selecting patients for enrolment into endovascular treatment trials that include only patients with a high ASPECTS value [27-29]. In a subgroup analysis of another endovascular treatment trial, the odds ratio favoring the intervention was higher in patients with lower ASPECTS value [30].

However, the fact that detecting early ischemic changes from non-contrast CT scan requires expertise from the clinician is an important reason for the limited application of ASPECTS. Therefore, the electronic ASPECTS (e-ASPECTS) software was developed for providing a standardized, fully automated decision-support tool [31]. The performance of the e-ASPECTS software has been shown to be equivalent in sensitivity and specificity to the manual interpretation of non-contrast CT scans by trained stroke physicians and neuroradiologists when diffusionweighted MRI is used as a ground truth reference [32].

A recent editorial proposed that the integration of ASPECTS into the MSU concept could potentially increase neuroradiological competence during the prehospital phase of stroke management [33]. In this study, the feasibility of incorporating an automated stroke imaging software (e-ASPECTS, Brainomix Ltd., Oxford, UK) into the MSU concept was assessed for the first time and its clinical use for the treatment of acute stroke patients directly at the emergency site evaluated.

\section{Methods and Patients}

Patients and Context of the Investigation

A total of 15 consecutive patients were evaluated for determining the feasibility and benefit of the e-ASPECTS software in stroke management in a MSU. Patients were studied in the context of a larger study of prehospital stroke treatment that was approved by the Ethical Committee of the Physicians' Chamber of Saarland. All patients provided written informed consent for participation.

\section{MSU Strategy}

The MSU is an ambulance equipped with all the standard tools for emergency care with the following special equipments: (i) an accumulator-driven and lead-shielded CT scanner (CereTom, NeuroLogica/Samsung, Danvers, Mass., USA), allowing multimodal imaging; (ii) a telemedicine system (MEYTEC, Werneuchen, Germany), enabling the transmission of digital imaging and communication data obtained by CT scanning or video of clinical examination via the universal mobile telecommunication system to the picture archiving and communication system of the hospital; and (iii) a point-of-care laboratory system for measuring the platelet count, leukocyte count, erythrocyte count, hemoglobin level, and hematocrit (PocH 100i, Sysmex, Hamburg, Germany); international normalized ratio (INR) and activated partial thromboplastin time (Hemochron Jr., ITC, Edison, N.Y., USA); and $\gamma$ glutamyltransferase activity, p-amylase activity, and glucose concentration (Reflotron Plus, Roche Diagnostics Mannheim, Germany) [3, 6].

The emergency medical service (EMS) dispatch center dispatches the MSU in parallel with the regular EMS to assess patients with suspected acute stroke.

\section{Implementation of e-ASPECTS Software in a MSU}

The e-ASPECTS software (Brainomix Ltd., Oxford, UK) automates the ASPECTS method. It is a fully automated, topographic, quantitative, and Conformité Européene (CE)-marked scoring tool for detecting early ischemic damage on CT scans. This raterindependent software was developed for standardizing the interpretation of CT scans and for making the interpretation readily 
available. Following pre-processing of input images, a registration step corrects for any 3D rotation and misalignment (e.g. tilt). Image features are then extracted and regions are scored with a machine learning classifier that identifies early ischemic signs.

Non-contrast enhanced scans were obtained with the MSU's Ceretom scanner and then evaluated using the e-ASPECTS software. Two integration approaches were investigated, both using the native continuous spiral data acquisition protocol on the scanner, resulting in a minimal slice thickness of $1.25 \mathrm{~mm}$. The first integration approach is based on the use of a laptop computer with an Intel Core i7 processor as the e-ASPECTS server. To avoid changing the configuration of other MSU devices, a manual workflow was implemented in which scans were exported from the viewing workstation on the MSU, compressed, and uploaded through the e-ASPECTS web-based user interface (UI) by hand. Results were then viewed through the viewing workstation, again using the e-ASPECTS web-based UI. The second integration approach supported a streamlined workflow. Scans were pushed via the Digital Imaging and Communications in Medicine (DICOM) network protocol to the e-ASPECTS server over a standard local area network connection. The server automatically processed the images and pushed annotated result images back to the viewing workstation, again over the DICOM network protocol. It was also possible to generate e-mail notifications containing anonymized images, if necessary. This approach considerably simplified the user workflow, although it required reconfiguring the network and devices in the MSU to allow DICOM communication to e-ASPECTS.

The standardized topographic scoring system, ASPECTS, divides the territory of MCA into 10 areas of interest within 2 specified levels: the level of the basal ganglia and the level of the supraganglionic structure [20]. Analysis of each region of the brain for signs of ischemic damage generates the ASPECTS value. Additional details of the software have been described elsewhere [31, 32].

In this study, the e-ASPECTS values were also compared with the results obtained by neuroradiologists (A.R.-S., M.K., S.R.) on the MSU team, who manually analyzed the scans for early signs of infarction.

\section{Results}

Obtaining e-ASPECTS Values of Patients with Acute Stroke Symptoms

Fifteen consecutive patients ( 2 men, 13 women) with symptoms of acute stroke were examined in the MSU with e-ASPECTS. The median age of the patients was 82 years (interquartile range (IQR) 71-85 years). The patients' median score on the National Institutes of Health Stroke Scale (NIHSS) was 4 (IQR 1-6); and that on the Los Angeles Motor Scale (LAMS) was 1 (IQR 0-4).

For these patients, the median stroke management times were as follows: time from symptom onset to alarm, $54 \mathrm{~min}$ (IQR 19-125 $\mathrm{min}$ ); time from symptom onset to MSU arrival, $64 \mathrm{~min}$ (IQR 30-159 min); time from symptom onset to CT scan, $93 \mathrm{~min}$ (IQR 62-181 min); and time from symptom onset to thrombolysis, $85 \mathrm{~min}$ (IQR 58-154 min).

Twelve patients scored an e-ASPECTS value of 10;1 scored a value of 9. Obtaining an e-ASPECTS value for the other 2 patients was not possible because of the poor quality of source CT images. These e-ASPECTS values matched with the results of conventional evaluation by neuroradiologists on the MSU team.

Three exemplary clinical cases are presented below.

Case 1. e-ASPECTS Value Suggesting Absence of Early Signs of Infarction Assisted in the Decision to Perform

Prehospital IV Thrombolysis

A 71-year-old woman collapsed. Neurological examination by the MSU team found right-sided facial paresis and hemiparesis (grade 0/5) and mild dysarthria (NIHSS score 16; modified Rankin Scale (mRS) score 5; LAMS score 5). Results of point-of-care laboratory tests (INR, activated partial thromboplastin time, glucose level, leukocyte count, platelet count, erythrocyte count, p-amylase activity, and $\gamma$-glutamyltransferase activity) were normal.

The prehospital scans showed no intracranial bleeding, no demarcation of cerebral contusion, and no new infarction (fig. 1a). CT angiography showed no large-vessel occlusion. The e-ASPECTS value was 10 (fig. 1b). The therapy decision was prehospital thrombolysis.

The following time metrics of stroke management were obtained: time from symptom onset to alarm, 14 min; time from symptom onset to MSU arrival, $23 \mathrm{~min}$; time from symptom onset to CT scan, $57 \mathrm{~min}$; and time from symptom onset to thrombolysis, $59 \mathrm{~min}$.

The patient responded well to thrombolytic treatment and was discharged after 1 week with no neurological deficit (NIHSS score 0; mRS score 0).

\section{Case 2. e-ASPECTS Value Suggesting Absence}

of Early Infarct Signs in an Acute Stroke Patient with

Large-Vessel Occlusion Assisted in Decision for Bridging

IV Thrombolysis and Triage to a Comprehensive Stroke

\section{Center for Intra-Arterial Treatment}

Upon arrival, the MSU team found a 73-year-old woman on the floor. Neurological examination found a right-sided hemiparesis (grade 1/5), global aphasia, mild somnolence, and ocular deviation to the left side (NIHSS score 20; LAMS score 4). Results of point-of-care laboratory tests were normal.

The CT scans showed no intracranial bleeding, no demarcation of cerebral contusion, and no infarction (fig. 1c); however, a proximal (M1) occlusion of the left 
Fig. 1. Axial unenhanced CT images acquired in the prehospital setting of the MSU (left panel), and e-ASPECTS segmentation of these images (right panel). a, b The e-ASPECTS software showed that no early infarct signs were present (ASPECTS value, 10) and assisted in the decision for prehospital thrombolysis in a patient with acute stroke. c, d For a patient with acute stroke caused by large-vessel occlusion, an e-ASPECTS value of 10 assisted in the decision for prehospital bridging thrombolysis, followed by intra-arterial treatment in a comprehensive stroke center. e, f For an acute stroke patient with signs of pre-existing cerebral microangiopathy and older ischemic lesions in the left MCA territory, detection of early ischemic signs was difficult. However, an eASPECTS value of 10 assisted in the interpretation against early infarct signs and in making the decision to treat the patient with prehospital thrombolysis.

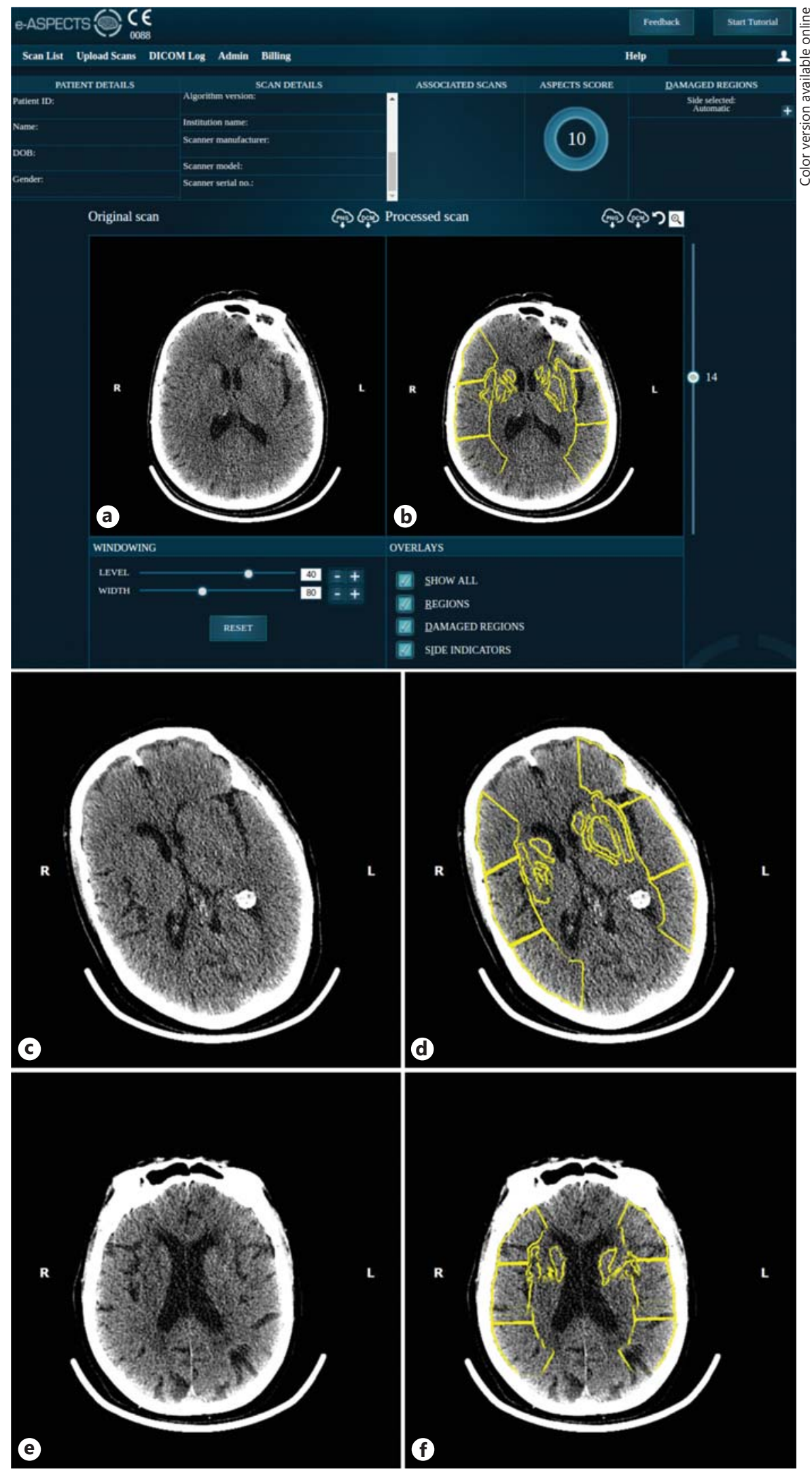

Cerebrovasc Dis 2016;42:332-338
First Automated Stroke Imaging Evaluation via e-ASPECTS in a MSU 
MCA was visible upon CT angiography. The e-ASPECTS value was 10 (fig. 1d). Because CT ruled out hemorrhage and e-ASPECTS confirmed the absence of early signs of infarction, the therapy decision was immediate bridging thrombolysis and triage to the closest comprehensive stroke center for subsequent intra-arterial treatment.

The following time metrics of stroke management were determined: time from symptom onset to alarm, 56 $\mathrm{min}$; time from symptom onset to MSU arrival, $75 \mathrm{~min}$; time from symptom onset to CT, $90 \mathrm{~min}$; time from symptom onset to bridging thrombolysis, $95 \mathrm{~min}$; time from symptom onset to arrival at the comprehensive stroke center, $133 \mathrm{~min}$; and time from symptom onset to groin puncture, $165 \mathrm{~min}$.

Upon discharge to a rehabilitation facility after 10 days, the patient's aphasia had improved slightly, although the hemiparesis persisted (NIHSS score 14; mRS score 5).

Case 3. e-ASPECTS Indicating Absence of Early Infarct Signs Despite Pre-Existing Older Cerebral Microangiopathy and Macroangiopathy in CT

An 89-year-old woman reported acute onset of beginning paresis of the left extremities. Neurological examination found paresis of the left arm (grade 4/5) and left leg (grade 0/5), but no sensory deficits (NIHSS score 5; LAMS score 2). The results of all point-of-care laboratory tests were normal.

Prehospital CT images showed no intracranial bleeding and no demarcation of cerebral contusion; however, they showed pre-existing pronounced cerebral microangiopathy and signs of older ischemic lesions in the left MCA territory (fig. 1e). The e-ASPECTS value was 10 (fig. 1f), a value suggestive of the absence of early signs of infarction. The therapy decision was immediate prehospital thrombolysis.

The time metrics of stroke management were: time from symptom onset to alarm, $28 \mathrm{~min}$; time from symptom onset to MSU arrival, $37 \mathrm{~min}$; time from symptom onset to CT scan, $66 \mathrm{~min}$; and time from symptom onset to thrombolysis, $100 \mathrm{~min}$. After 1 week, the patient's neurological status improved with a grade $4 / 5$ paresis left arm and grade 3/5 paresis left leg (NIHSS score 3; mRS score 3 ).

\section{Discussion}

Correct identification of early signs of demarcating cerebral infarction is important in selecting patients for recanalization treatment. Because the administration of prehospital thrombolysis is increasingly being studied at many stroke centers in several countries [3, 6-14], the availability of a tool that could evaluate CT images and detect signs of infarction in an ambulance in a standardized manner would be of considerable medical interest. This study demonstrates the feasibility and potential clinical benefit of integrating the e-ASPECTS software for the automated detection of early ischemic damage in a MSU.

Obtaining an ASPECTS value in the prehospital stage of stroke management was possible for 13 of the 15 patients. In 2 cases, images were severely impaired by headmovement artefact, precluding both manual and automated ASPECTS scoring. Movement artefacts are sometimes a problem in agitated patients, and it was found that the software correctly alerted to their presence. Most of the patients included in this study had an e-ASPECTS value of 10 . The scores matched with the results of manual interpretation of early signs of infarction on the CT images by the neuroradiologists on board the MSU.

All patients in this series had high e-ASPECTS values, a finding that can be explained by the fact that for all 15 patients the time between stroke onset and CT imaging was short. The median time from symptom onset to CT imaging for the study patients was 93 min (IQR 62-181 $\mathrm{min}$ ). This work was part of the prehospital stroke treatment program in which the MSU was dispatched mainly to hyperacute stroke patients. Moreover, the response times of the MSU and the times to diagnostic work-up are faster than those in the conventional hospital approach [6-14]. Indeed, the finding of very high e-ASPECTS values matched with the findings of median scores of 9 in a recent thrombectomy study, in which response times were also very short (median symptom onset-to-needle times of $85 \mathrm{~min}$ ) [30].

The exemplary cases illustrate the potential of this automated, rater-independent imaging software in assisting the MSU team in both therapy decisions and triage decisions directly at the emergency site. Case 1 illustrates the potential medical benefit of excluding early signs of infarction with e-ASPECTS software, thereby assisting the MSU team in making a decision for immediate prehospital thrombolysis of acute ischemic stroke.

According to recent evidence, endovascular stroke therapy for the anterior circulation is likely to become the 'new standard of care' for patients with large-vessel occlusion [34]. Because appropriate patient selection for endovascular treatment is crucial, the e-ASPECTS software could also be beneficial in this regard, thereby standardizing patient care $[27,30,31,35]$. In case 2 , the software supported the decision to provide bridging IV thrombolysis followed by endovascular treatment in a comprehen- 
sive stroke center for an acute stroke patient with largevessel occlusion and no early signs of infarction. Thus, apart from therapy decisions, e-ASPECTS software can assist in triage decisions with regard to the most appropriate target hospital, for example, comprehensive stroke unit vs. primary stroke unit.

Finally, for one acute stroke patient, manual interpretation of the CT images was difficult because of marked signs of pre-existing older cerebral microangiopathy and macroangiopathy. The e-ASPECTS value was 10 , a finding indicating the robustness of this scoring tool against potential sources of non-acute ischemic hypodensities. This patient was treated with thrombolysis directly at the emergency site with marked clinical benefit.

It was not the aim of this study to evaluate accuracy of the e-ASPECTS software as the software is already CE marked as a decision support tool for the detection of early ischemic damage, and the performance has been validated as part of the CE marking process. In addition, Herweh et al. [32] demonstrated in an independent study that the performance of e-ASPECTS is equivalent to expert neuroradiologists.

In prehospital stroke treatment, neuroradiological competence may be provided in several ways, for example, by the presence of specifically trained physicians in the ambulance $[3,5]$ or by telemedicine support for the MSU team so that images can be evaluated by experts in the hospital. In the United States, the latter approach has recently been shown to be very reliable because of the widespread availability of $4 \mathrm{G}$ connectivity and the prioritization of EMS telecommunications [13]. In both configurations, the e-ASPECTS software could be a valuable second-opinion instrument that could assist the physician in making an assessment.

\section{Conclusion}

This preliminary report shows for the first time that integrating e-ASPECTS software into a MSU is feasible and can provide information relevant to decisions regarding prehospital stroke treatment and selection of the most appropriate target hospital.

\section{Disclosure Statement}

I.Q. Grunwald is the Medical Director and Co-Founder of Brainomix Ltd. E. Greveson is the Chief Technical Officer of Brainomix Ltd.

\section{Funding}

Ministry of Health, Saarland, Germany.

\section{References}

1 Saver JL: Time is brain - quantified. Stroke 2006; 37:263-266.

2 Fassbender K, Walter S, Liu Y, Muehlhauser F, Ragoschke A, Kuehl S, Mielke O: 'Mobile stroke unit' for hyperacute stroke treatment. Stroke 2003;34:e44.

3 Walter S, Kostpopoulos P, Haass A, Helwig S, Keller I, Licina T, Schlechtriemen T, Roth C, Papanagiotou P, Zimmer A, Viera J, Körner H, Schmidt K, Romann MS, Alexandrou M, Yilmaz U, Grunwald I, Kubulus D, Lesmeister M, Ziegeler S, Pattar A, Golinski M, Liu Y, Volk T, Bertsch T, Reith W, Fassbender K: Bringing the hospital to the patient: first treatment of stroke patients at the emergency site. PLoS One 2010;5:e13758.

4 Rumboldt Z, Huda W, All JW: Review of portable CT with assessment of a dedicated head CT scanner. AJNR Am J Neuroradiol 2009; 30:1630-1636.

5 Walter S, Kostopoulos P, Haass A, Lesmeister M, Grasu M, Grunwald I, Keller I, Helwig S, Becker C, Geisel J, Bertsch T, Kaffiné S, Leingärtner A, Papanagiotou P, Roth C, Liu Y, Reith W, Fassbender K: Point-of-care lab- oratory halves door-to-therapy-decision time in acute stroke. Ann Neurol 2011;69: 581-586.

6 Walter S, Kostopoulos P, Haass A, Keller I, Lesmeister M, Schlechtriemen T, Roth C, Papanagiotou P, Grunwald I, Schumacher H, Helwig S, Viera J, Körner H, Alexandrou M, Yilmaz U, Ziegler K, Schmidt K, Dabew R, Kubulus D, Liu Y, Volk T, Kronfeld K, Ruckes C, Bertsch T, Reith W, Fassbender K: Diagnosis and treatment of patients with stroke in a mobile stroke unit versus in hospital: a randomised controlled trial. Lancet Neurol 2012; 11:397-404.

7 Bowry R, Parker S, Rajan SS, Yamal JM, Wu TC, Richardson L, Noser E, Persse D, Jackson K, Grotta JC: Benefits of stroke treatment using a mobile stroke unit compared with standard management: the BEST-MSU study runin phase. Stroke 2015;46:3370-3374.

8 Cerejo R, John S, Buletko AB, Taqui A, Itrat A, Organek N, Cho SM, Sheikhi L, Uchino K, Briggs F, Reimer AP, Winners S, Toth G, Rasmussen $P$, Hussain MS: A mobile stroke treatment unit for field triage of patients for intra- arterial revascularization therapy. J Neuroimaging 2015;25:940-945.

9 Ebinger M, Winter B, Wendt M, Weber JE, Waldschmidt C, Rozanski M, Kunz A, Koch P, Kellner PA, Gierhake D, Villringer K, Fiebach JB, Grittner U, Hartmann A, Mackert BM, Endres M, Audebert HJ; STEMO Consortium: Effect of the use of ambulance-based thrombolysis on time to thrombolysis in acute ischemic stroke: a randomized clinical trial. JAMA 2014;311:1622-1631.

10 Ebinger M, Kunz A, Wendt M, Rozanski M, Winter B, Waldschmidt C, Weber J, Villringer K, Fiebach JB, Audebert HJ: Effects of golden hour thrombolysis: a prehospital acute neurological treatment and optimization of medical care in stroke (PHANTOM-S) substudy. JAMA Neurol 2015;72:25-30.

11 Gomes JA, Ahrens CL, Hussain MS, Winners S, Rasmussen PA, Uchino K; Cleveland PreHospital Acute Stroke Treatment Study Group: Prehospital reversal of warfarin-related coagulopathy in intracerebral hemorrhage in a mobile stroke treatment unit. Stroke 2015;46:e118-e120.
First Automated Stroke Imaging

Evaluation via e-ASPECTS in a MSU
Cerebrovasc Dis 2016;42:332-338 DOI: $10.1159 / 000446861$ 
12 Hov MR, Nome T, Zakariassen E, Russell D, Røislien J, Lossius HM, Lund CG: Assessment of acute stroke cerebral CT examinations by anaesthesiologists. Acta Anaesthesiol Scand 2015;59:1179-1186.

13 Itrat A, Taqui A, Cerejo R, Briggs F, Cho SM, Organek N, Reimer AP, Winners S, Rasmussen P, Hussain MS, Uchino K; Cleveland Pre-Hospital Acute Stroke Treatment (PHAST) Group: Telemedicine in prehospital stroke evaluation and thrombolysis: taking stroke treatment to the doorstep. JAMA Neurol 2016;73:162-168.

14 Parker SA, Bowry R, Wu TC, Noser EA, Jackson K, Richardson L, Persse D, Grotta JC: Establishing the first mobile stroke unit in the United States. Stroke 2015;46:1384-1391.

15 Patel SC, Levine SR, Tilley BC, Grotta JC, Lu M, Frankel M, Haley EC Jr, Brott TG, Broderick JP, Horowitz S, Lyden PD, Lewandowski CA, Marler JR, Welch KM; National Institute of Neurological Disorders and Stroke rt-PA Stroke Study Group: Lack of clinical significance of early ischemic changes on computed tomography in acute stroke. JAMA 2001;286: 2830-2838.

16 Hacke W, Kaste M, Fieschi C, Toni D, Lesaffre E, von Kummer R, Boysen G, Bluhmki E, Höxter G, Mahagne MH, et al: Intravenous thrombolysis with recombinant tissue plasminogen activator for acute hemispheric stroke. The European cooperative acute stroke study (ECASS). JAMA 1995;274:1017-1025.

17 Grunwald I, Reith W: Non-traumatic neurological emergencies: imaging of cerebral ischemia. Eur Radiol 2002;12:1632-1647.

18 Grotta JC, Chiu D, Lu M, Patel S, Levine SR, Tilley BC, Brott TG, Haley EC Jr, Lyden PD, Kothari R, Frankel M, Lewandowski CA, Libman R, Kwiatkowski T, Broderick JP, Marler JR, Corrigan J, Huff S, Mitsias P, Talati S, Tanne D: Agreement and variability in the interpretation of early CT changes in stroke patients qualifying for intravenous rtPA therapy. Stroke 1999;30:1528-1533.

19 Mullins ME, Lev MH, Schellingerhout D, Koroshetz WJ, Gonzalez RG: Influence of availability of clinical history on detection of early stroke using unenhanced CT and diffusionweighted MR imaging. AJR Am J Roentgenol 2002;179:223-228.

20 Barber PA, Demchuk AM, Zhang J, Buchan AM: Validity and reliability of a quantitative computed tomography score in predicting outcome of hyperacute stroke before thrombolytic therapy. ASPECTS study group. alberta stroke programme early CT score. Lancet 2000;355:1670-1674.

21 MacCallum C, Churilov L, Mitchell P, Dowling $\mathrm{R}$, Yan B: Low alberta stroke program early CT score (ASPECTS) associated with malignant middle cerebral artery infarction. Cerebrovasc Dis 2014;38:39-45.
22 Rusanen H, Saarinen JT, Sillanpää N: Collateral circulation predicts the size of the infarct core and the proportion of salvageable penumbra in hyperacute ischemic stroke patients treated with intravenous thrombolysis. Cerebrovasc Dis 2015;40:182-190.

23 Hill MD, Rowley HA, Adler F, Eliasziw M, Furlan A, Higashida RT, Wechsler LR, Roberts HC, Dillon WP, Fischbein NJ, Firszt CM, Schulz GA, Buchan AM; PROACT-II Investigators: Selection of acute ischemic stroke patients for intra-arterial thrombolysis with pro-urokinase by using ASPECTS. Stroke 2003;34:1925-1931.

24 Okazaki S, Moriwaki H, Minematsu K, Naritomi H: Extremely early computed tomography signs in hyperacute ischemic stroke as a predictor of parenchymal hematoma. Cerebrovasc Dis 2008;25:241-246.

25 Hill MD, Buchan AM; Canadian Alteplase for Stroke Effectiveness Study (CASES) Investigators: Thrombolysis for acute ischemic stroke: results of the Canadian alteplase for stroke effectiveness study. CMAJ 2005;172: 1307-1312.

26 Casaubon LK, Boulanger JM, Blacquiere D, Boucher S, Brown K, Goddard T, Gordon J, Horton $\mathrm{M}$, Lalonde J, LaRivière $\mathrm{C}$, Lavoie $\mathrm{P}$, Leslie P, McNeill J, Menon BK, Moses B, Penn M, Perry J, Snieder E, Tymianski D, Foley N, Smith EE, Gubitz G, Hill MD, Glasser E, Lindsay P; Heart and Stroke Foundation of Canada Canadian Stroke Best Practices Advisory Committee: Canadian stroke best practice recommendations: hyperacute stroke care guidelines, update 2015. Int J Stroke 2015;10: 924-940.

27 Goyal M, Demchuk AM, Menon BK, Eesa M, Rempel JL, Thornton J, Roy D, Jovin TG, Willinsky RA, Sapkota BL, Dowlatshahi D, Frei DF, Kamal NR, Montanera WJ, Poppe AY, Ryckborst KJ, Silver FL, Shuaib A, Tampieri D, Williams D, Bang OY, Baxter BW, Burns $\mathrm{PA}$, Choe H, Heo JH, Holmstedt CA, Jankowitz B, Kelly M, Linares G, Mandzia JL, Shankar J, Sohn SI, Swartz RH, Barber PA, Coutts SB, Smith EE, Morrish WF, Weill A, Subramaniam S, Mitha AP, Wong JH, Lowerison MW, Sajobi TT, Hill MD; ESCAPE Trial Investigators: Randomized assessment of rapid endovascular treatment of ischemic stroke. $\mathrm{N}$ Engl J Med 2015;372:1019-1030.

28 Saver JL, Goyal M, Bonafe A, Diener HC, Levy EI, Pereira VM, Albers GW, Cognard C, Cohen DJ, Hacke W, Jansen O, Jovin TG, Mattle HP, Nogueira RG, Siddiqui AH, Yavagal DR, Baxter BW, Devlin TG, Lopes DK, Reddy VK, du Mesnil de Rochemont R, Singer OC, Jahan R; SWIFT PRIME Investigators: Stent-retriever thrombectomy after intravenous $\mathrm{t}-\mathrm{PA}$ vs. t-PA alone in stroke. N Engl J Med 2015; 372:2285-2295.
29 Jovin TG, Chamorro A, Cobo E, de Miquel MA, Molina CA, Rovira A, San Román L, Serena J, Abilleira S, Ribó M, Millán M, Urra X, Cardona P, López-Cancio E, Tomasello A, Castaño C, Blasco J, Aja L, Dorado L, Quesada H, Rubiera M, Hernandez-Pérez M, Goyal M, Demchuk AM, von Kummer R, Gallofré M, Dávalos A; REVASCAT Trial Investigators: Thrombectomy within 8 hours after symptom onset in ischemic stroke. N Engl J Med 2015;372:2296-2306.

30 Berkhemer OA, Fransen PS, Beumer D, van den Berg LA, Lingsma HF, Yoo AJ, Schonewille WJ, Vos JA, Nederkoorn PJ, Wermer MJ, van Walderveen MA, Staals J, Hofmeijer J, van Oostayen JA, Lycklama à Nijeholt GJ, Boiten J, Brouwer PA, Emmer BJ, de Bruijn SF, van Dijk LC, Kappelle LJ, Lo RH, van Dijk EJ, de Vries J, de Kort PL, van Rooij WJ, van den Berg JS, van Hasselt BA, Aerden LA, Dallinga RJ, Visser MC, Bot JC, Vroomen PC, Eshghi O, Schreuder TH, Heijboer RJ, Keizer K, Tielbeek AV, den Hertog HM, Gerrits DG, van den Berg-Vos RM, Karas GB, Steyerberg EW, Flach HZ, Marquering HA, Sprengers ME, Jenniskens SF, Beenen LF, van den Berg R, Koudstaal PJ, van Zwam WH, Roos YB, van der Lugt $A$, van Oostenbrugge RJ, Majoie CB, Dippel DW; MR CLEAN Investigators: A randomized trial of intraarterial treatment for acute ischemic stroke. N Engl J Med 2015;372: $11-20$.

31 Hampton-Till J, Harrison M, Kühn AL, Anderson O, Sinha D, Tysoe S, Greveson E, Papadakis M, Grunwald IQ: Automated quantification of stroke damage on brain computed tomography scans: e-ASPECTS. EMJ Neurol 2015;3:69-74.

32 Herweh C, Ringleb PA, Rauch G, Gerry S, Behrens L, Möhlenbruch M, Gottorf R, Richter D, Schieber S, Nagel S: Performance of eASPECTS software in comparison to that of stroke physicians on assessing CT scans of acute ischemic stroke patients. Int J Stroke 2016;11:438-445.

33 Rothwell PM, Buchan AM: Mobile acute stroke units: bringing the hospital to the patient. Lancet Neurol 2012;11:382-383.

34 Campbell BC, Donnan GA, Lees KR, Hacke W, Khatri P, Hill MD, Goyal M, Mitchell PJ, Saver JL, Diener HC, Davis SM: Endovascular stent thrombectomy: the new standard of care for large vessel ischaemic stroke. Lancet Neurol 2015;14:846-854.

35 Balami JS, Sutherland BA, Edmunds LD, Grunwald IQ, Neuhaus AA, Hadley G, Karbalai H, Metcalf KA, DeLuca GC, Buchan AM: A systematic review and meta-analysis of randomized controlled trials of endovascular thrombectomy compared with best medical treatment for acute ischemic stroke. Int J Stroke 2015;10:1168-1178. 